\title{
Studi Awal Pengukuran Daisy Chaining Detektor Ionisasi pada Berkas Foton 6 MV Flattening Filter Free Lapangan Kecil
}

\section{Assef Firnando Firmansyah ${ }^{1}$, Okky Agassy Firmansyah ${ }^{1}$, Nurman Rajagukguk ${ }^{1}$, Dea Ryangga ${ }^{2}$}

${ }^{1}$ PTKMR BATAN, Jalan Lebak Bulus Raya No. 49, Jakarta

${ }^{2}$ RSUD Pasar Minggu, Jalan TB. Simatupang No. 1, Jakarta

\section{Info Artikel}

\section{Histori Artikel:}

Diterima: 19 September, 2019

Direvisi: 27 November, 2019

Diterbitkan: 1 Maret, 2020

\section{Kata kunci:}

daisy chaining

lapangan radiasi kecil

berkas foton tanpa filter perata

laju dosis serap air

faktor kalibrasi
Keywords:

daisy chaining

small field

flattening filter free photon beam absorbed dose to water calibration factor

Penulis Korespondensi:

Okky Agassy Firmansyah Email: okky-agassy@ batan.go.id

\begin{abstract}
ABSTRAK
Salah satu alternatif untuk melakukan kalibrasi detektor ionisasi kecil pada lapangan radiasi kecil adalah dengan melakukan pengukuran daisy chaining. Makalah ini menguraikan pengukuran daisy chaining detektor ionisasi kecil pada berkas foton $6 \mathrm{MV}$ flattening filter free lapangan radiasi kecil. Langkah pertama pengukuran daisy chaining adalah melakukan kalibrasi detektor ionisasi medium $0,13 \mathrm{~cm}^{3}$ terhadap detektor ionisasi standar $0,6 \mathrm{~cm}^{3}$ pada lapangan radiasi $10 \mathrm{~cm} \times 10 \mathrm{~cm}$. Setelah mendapatkan faktor kalibrasi dosis serap air $\left(\mathrm{N}_{\mathrm{D}, \mathrm{W}}\right)$ dari detektor ionisasi medium, langkah berikutnya adalah menggunakan $\mathrm{N}_{\mathrm{D}, \mathrm{W}}$ tersebut untuk mengalibrasi silang detektor ionisasi mikro $0,016 \mathrm{~cm}^{3}$ pada lapangan $5 \mathrm{~cm} \times 5 \mathrm{~cm}$. $\mathrm{N}_{\mathrm{D}, \mathrm{W}}$ hasil kalibrasi tersebut dapat digunakan untuk pengukuran di lapangan radiasi kurang dari $5 \mathrm{~cm} \times 5 \mathrm{~cm}$. Penentuan laju dosis serap air dilakukan di lapangan $3 \mathrm{~cm} \times 3 \mathrm{~cm}$ dan $2 \mathrm{~cm} \times 2$ $\mathrm{cm}$. Verifikasi dilakukan dengan membandingkan hasil penentuan laju dosis serap air menggunakan $\mathrm{N}_{\mathrm{D}, \mathrm{W}}$ hasil pengukuran daisy chaining, pengukuran langsung menggunakan $\mathrm{N}_{\mathrm{D}, \mathrm{W}}$ detektor ionisasi tanpa pengukuran daisy chaining dan hasil perhitungan dari treatment planning system (TPS). Hasil yang diperoleh menunjukkan adanya perbedaan antara pengukuran daisy chaining, pengukuran langsung, dan hasil perhitungan TPS. Perbedaan masih dalam rentang kurang dari $3 \%$.
\end{abstract}

One of alternative to calibrate a small field ionization chamber was to make daisy chaining measurements. This paper describes the daisy chaining measurements of a small field ionization chamber in a $6 \mathrm{MV}$ photon flattening filter free. The first step in the daisy chaining measurement was to calibrate the medium ionization chamber $0.13 \mathrm{~cm}^{3}$ against a standard ionization chamber $0.6 \mathrm{~cm}^{3}$ at field size $10 \mathrm{~cm} \times 10 \mathrm{~cm}$. After obtaining the calibration factor for absorbed dose to water $\left(N_{D, W}\right)$ from the medium ionization chamber, the next step was to use the $N_{D, W}$ to cross calibrate the micro ionization chamber 0.016 $\mathrm{cm}^{3}$ at $5 \mathrm{~cm} \times 5 \mathrm{~cm}$ field size. $N_{D, W}$ calibration results can be used for measurements in the radiation field less than $5 \mathrm{~cm} \times 5 \mathrm{~cm}$. The determination of the absorbed dose to water rate was done in the $3 \mathrm{~cm} \times 3 \mathrm{~cm}$ and $2 \mathrm{~cm} \times 2$ $\mathrm{cm}$ field size. Verification was done by comparing the results of determination of the absorbed dose to water using $N_{D, W}$ measurement as results of daisy chaining, direct measurements using $N_{D, W}$ ionization detectors without daisy chaining measurements and the results of calculations from the treatment planning system (TPS). The results obtained indicate the difference between daisy chaining measurements, direct measurements, and the results of TPS calculations. The difference was still in the range of less than $3 \%$. 


\section{PENDAHULUAN}

Di Indonesia perkembangan penggunaan lapangan radiasi kecil dalam radioterapi begitu cepat (Assef, dkk. 2017). Hingga pertengahan tahun 2019, terdapat empat rumah sakit yang telah memiliki pesawat pemercepat linier medik tanpa filter perata berkas radiasi (flattening filter free/FFF). Salah satu kelebihan dari pesawat linier medik FFF adalah dapat digunakan untuk penyinaran lapangan kecil hingga 15 mm - 0,5 mm menggunakan kolimator stereotactic conical (Borzov, 2018).

Pesawat linier medik FFF memiliki laju dosis yang lebih tinggi dari pada pesawat pemercepat linier medik FF(Firmansyah,dkk 2018; Papanikolaou, 2016). Laju dosis tinggi tersebut dapat dimanfaatkan untuk mempersingkat waktu penyinaran kepada pasien dan jaringan sehat juga lebih terlindungi. Namun demikian, kualitas berkas foton dari pesawat pemercepat linier medik FFF lebih rendah dari pada pesawat pemercepat linier medik FF (Firmansyah, dkk., 2017; Sharma, dkk., 2016). Proses pengukuran luaran berkas radiasi pesawat ini juga membutuhkan perilaku khusus, seperti penggunaan faktor koreksi untuk jenis detektor yang digunakan (Firmansyah, dkk., 2019).

Untuk menentukan parameter dosimetri pada lapangan radiasi kecil diperlukan detektor dengan volume yang kecil juga (Das I.J, 2018). Sampai saat ini detektor yang digunakan untuk pengukuran absolut pesawat teleterapi masih dikalibrasi terhadap detektor standar pada kondisi acuan dengan lapangan radiasi di permukaan fantom $10 \mathrm{~cm}$ x $10 \mathrm{~cm}$, jarak sumber radiasi ke permukaan fantom (source to surface distance $/ \mathrm{SSD}$ ) $100 \mathrm{~cm}$.

Untuk detektor dengan volume kecil, khususnya detektor dioda, kalibrasi pada kondisi standar dipandang sudah tidak sesuai lagi, karena detektor standar yang digunakan untuk kalibrasi volumenya jauh lebih besar dari detektor volume kecil, demikian juga dengan lapangan radiasinya yang jauh lebih besar dari penggunaan detektor volume kecil tersebut (Liu, dkk, 2016). Hal lain yang menjadi masalah adalah ketertelusuran untuk lapangan radiasi kecil ke laboratorium standar primer masih dalam penelitian. Faktor koreksi untuk detektor radiasi lapangan kecil juga masih terbatas, belum seluruhnya terdapat pada protokol International Atomic Energy Agency (IAEA) Technical Report Series (TRS) no. 483 .

Salah satu referensi menyatakan bahwa detektor ionisasi volume kecil dapat digunakan secara langsung dan tidak langsung, namun untuk detektor diode harus menggunakan pengukuran tidak langsung (PTW, 2014). Pengukuran tidak langsung yang dimaksud adalah mengalibrasi silang detektor volume kecil terhadap detektor volume medium dengan lapangan radiasi yang lebih kecil dari lapangan acuan yang masih mampu dijangkau oleh detektor yang memenuhi kondisi kesetimbangan partikel bermuatan. Selanjutnya detektor volume kecil ini dapat digunakan untuk pengukuran pada lapangan yang lebih kecil dari pada lapangan kalibrasinya dan pada kedalaman yang lain namun untuk kualitas radiasi orientasi detektor yang sama. Pendekatan ini disebut juga dengan daisy chaining (Lárraga-Gutiérrez, 2015).

Makalah ini menguraikan studi awal pengukuran daisy chaining detektor ionisasi volume kecil pada berkas foton 6 MV (FFF) di lapangan kecil. Pengambilan data dilakukan dengan menggunakan pesawat pemercepat linier medik Varian Trilogy no. seri 6258 milik Rumah Sakit Umum Daerah Pasar Minggu, Jakarta. Tujuan dari penelitian ini adalah untuk memahami metode kalibrasi detektor ionisasi volume kecil dengan pengukuran daisy chaining serta observasi hasil penentuan laju dosis serap air di lapangan radiasi kecil menggunakan faktor kalibrasi tersebut.

\section{METODE}

\subsection{Kesetimbangan Partikel Bermuatan di Lateral (Lateral Charge Partikel Equilibrium)}

Keseimbangan partikel bermuatan pada bidang lateral, (Lateral Charge Partikel Equilibrium /LCPE) (satuan $\mathrm{mm}$ ) merupakan faktor yang sangat penting dalam pengukuran di lapangan radiasi kecil (Andreo, 2017; IAEA, 2017; Poppinga dkk., 2018). Kesetimbangan partikel bermuatan pada bidang lateral adalah kondisi fundamental yang harus dipenuhi pada pengukuran radiasi oleh sebuah detektor. Pada kondisi penyinaran lapangan radiasi kecil, tidak setimbangnya partikel bermuatan pada bidang pengukuran akan menjadi permasalahan yang akan mengakibatkan gangguan pada pengukuran oleh detektor. Permasalahan ini muncul ketika ukuran lebar penuh dari setengah tinggi maksimum 
(full width at half maximum/FWHM) dari berkas foton lebih kecil dari pada rentang maksimum pada bidang lateral dari berkas foton sekunder (Andreo, 2017).

Untuk mengatasi permasalahan ketidaksetimbangan partikel bermuatan di bidang lateral ini digunakanlah sebuah pendekatan matematis antara lebar lebar berkas radiasi dengan ukuran minimum detektor yang diperbolehkan untuk melakukan pengukuran pada kondisi tersedianya keseimbangan partikel bermuatan di bidang lateral. Pendekatan ini disebut dengan rentang keseimbangan partikel bermuatan pada bidang lateral, $r_{L C P E}$.

Melalui rentang keseimbangan partikel bermuatan pada bidang lateral, $r_{L C P E}$ (dalam $\mathrm{mm}$ ) dapat ditentukan hubungan antara lapangan radiasi dan dimensi minimal detektor yang digunakan agar syarat rentang keseimbangan partikel bermuatan pada bidang lateral terhadap sumbu utama berkas radiasi foton dipenuhi yang bergantung pada energi berkas radiasi. Hubungan ini dinyatakan dengan Persamaan 1 atau Persamaan 2 (IAEA, 2017)(Das \& Francescon, 2018).

$$
\begin{gathered}
r_{L C P E}=8,369 \times T P R_{20,10}(10)-4,328 \\
r_{L C P E}=77,97 \times 10^{-3} \times \% d d(10,10)_{x}-4,112
\end{gathered}
$$

Parameter \%dd $(10,10)_{x}$ merupakan nilai dosis pada fantom air dengan SSD $100 \mathrm{~cm}$. TPR 20,10 diidentifikasikan sebagai parameter untuk menyatakan kualitas radiasi berkas foton yang dapat diperoleh dari persamaan berikut:

$$
T P R_{20,10}=1,2661 \times P D D_{20,10}-0,0595
$$

Untuk menentukan laju dosis serap pada lapangan kecil maka lapangan radiasi dan detektor harus memenuhi hubungan sebagai berikut:

$$
F W H M=2 r_{L C P E}+d
$$

Sesuai dengan referensi (IAEA, 2017), parameter $d$ merupakan jarak terbesar diantara dua titik batas terluar dari geometri detektor. Nilai untuk geometri longitudinal $(d l)$ dihitung dengan persamaan:

$$
d l=l+t_{\text {wall }}
$$

Parameter $l$ adalah panjang rongga detektor (cavity length). Parameter $t_{\text {wall }}$ merupakan tebal dinding dari detektor ionisasi yang digunakan, sedangkan untuk nilai geometri radial $(d r)$ dihitung dengan menggunaka persamaaan:

$$
d r=2\left(r+t_{\text {wall }}\right)
$$

Berdasarkan kedua nilai geometri longitudinal $(d l)$ dan geometri radial $(d r)$ dapat dilihat mana yang lebih besar. Nilai terbesar tersebut digunakan sebagai nilai $d$ pada Persamaan 4 .

Sebagai contoh perhitungan dair referensi (IAEA, 2017), asumsi sebuah detektor ionisasi volume medium memiliki panjang rongga $l=4 \mathrm{~mm}$, jari-jari rongga $r=3 \mathrm{~mm}$, tebal dinding $t_{\text {wall }}=$ $0.07 \mathrm{~g} / \mathrm{cm}^{2}$, densitas material penyusun detektor C-552 $=1,76 \mathrm{~g} / \mathrm{cm}^{3}$, dan $t_{\text {wall }}=0,40 \mathrm{~mm}$. Untuk geometri longitudinal didapatkan $d l=l+t_{\text {wall }}=4,4 \mathrm{~mm}$, sedangkan untuk geometri radial $d r=$ $2\left(r+t_{\text {wall }}\right)=6,8 \mathrm{~mm}$. Berdasarkan data diketahui nilai $d r>d l$, maka nilai $d r=d$ untuk Persamaan 4 . Sehingga persamaan menjadi sebagai berikut.

$$
\begin{gathered}
F W H M=2 r_{L C P E}+d r \\
F W H M=2 r_{L C P E}+\left[2\left(r+t_{\text {wall }}\right)\right]
\end{gathered}
$$

\subsection{Tipe Detektor}

Pada dasarnya pengukuran profil berkas radiasi untuk lapangan radiasi kecil masih terkendala oleh adanya efek volume dari detektor yang digunakan. Hal tersebut juga dinyatakan oleh IAEA melalui protokol TRS No. 483 bahwa belum ada detektor yang ideal untuk pengukuran berkas radiasi di lapangan kecil. 
Berdasarkan beberapa literatur, terdapat beberapa hal yang dapat dilakukan untuk mereduksinya efek volume tersebut. Selain menggunakan perhitungan faktor koreksi dengan teknik dekonvolusi, pemilihan detektor volume kecil secara tepat juga dapat menjadi solusi. (IAEA, 2017; Lauba, 2003; Looe, 2010; Wuerfel, 2013).

Pemilihan jenis detektor volume kecil menjadi faktor yang perlu diperhatikan. Salah satu kelemahan dari pengukuran di lapangan radiasi kecil adalah adanya efek volume dari detektor. Pada dasarya detektor akan membaca sinyal rata-rata yang didapat dari partikel yang ter-ionisasi di seluruh volume aktif detektor. Apabila volume detektor lebih besar dari pada lapangan radiasi kecil, maka pembacaan muatan partikel oleh detektor tidak merata. Hal ini biasa disebut dengan efek volume ratarata (volume everaging effect)(Wuerfel, 2013). Efek volume ini dapat mengakibatkan pengukuran dosis pada titik referensi detektor tidak terpenuhi (underestimate dose), padahal nilai dosis tersebut penting untuk pengukuran output faktor dan dosis absolut sebagai referensi klinis.

Beberapa studi mengenai pengukuran daisy chaining mengelompokkan karakteristik detektor berdasarkan volume dan pengunaanya terhadap ukuran lapangan radiasi(Dieterich \& Sherouse, 2011; Lárraga-Gutiérrez, 2015; Wuerfel, 2013). Klasifikasi tersebut dimulai dari detektor ukuran standar, detektor ukuran medium dan detektor ukuran mikro. Namun dalam beberapa literatur lain menggunakan penamaan yang berbeda mengenai klasifikasi detektor (Purohit dkk., 2018). Pada penelitian ini penulis menggunakan klasifikasi detektor volume standar, detektor volume medium dan detektor volume kecil.

Protokol IAEA TRS No 398 menyatakan referensi untuk pengukuran dosis adalah pada lapangan radiasi $10 \mathrm{~cm}$ x $10 \mathrm{~cm}$. Detektor ionisasi standar yang biasa digunakan dalam pengukuran berkas foton pada lapangan standar ini adalah detektor ionisasi tipe farmer volume $0,6 \mathrm{~cm}^{3}$. Namun untuk lapangan radiasi kecil, terdapat beberapa tipe detektor dapat digunakan (PTW, 2014). Beberapa tipe detektor tersebut antara lain detektor ionisasi voume medium dan detektor ionisasi volume kecil.

Detektor ionisasi berukuran medium yang dikomersilkan biasanya memiliki volume antara 0,1 $\mathrm{cm}^{3}$ sampai dengan $1 \mathrm{~cm}^{3}$. Kelemahan detektor ini adalah volumenya yang relatif besar menyebabkan adanya efek volume jika digunakan untuk lapangan radiasi kecil. Bergantung pada model dari detektor ionisasi ini, untuk model Semiflex volume $0,125 \mathrm{~cm}^{3}$ dapat digunakan untuk lapangan radiasi sampai dengan $3 \mathrm{~cm} \times 3 \mathrm{~cm}$.

Detektor ionisasi berukuran kecil yang disebut juga sebagai detektor ionisasi mikro, contohnya adalah PTW Pinpoint 3D dengan volume pada orde $0,01 \mathrm{~cm}^{3}$. Detektor ini dapat digunakan untuk lapangan radiasi $2 \mathrm{~cm}$ x $2 \mathrm{~cm}$ sampai dengan $4 \mathrm{~cm}$ x $4 \mathrm{~cm}$. Detektor ini memiliki volume sampai dengan $0,001 \mathrm{~cm}^{3}$.

\subsection{Peralatan}

Sumber radiasi yang digunakan adalah pesawat pemercepat linier medik Varian Trilogy no. seri 6258 yang dapat memancarkan berkas foton $6 \mathrm{MV}$ FFF. Alat ukur radiasi yang digunakan adalah detektor ionisasi volume $0,6 \mathrm{~cm}^{3}$ model TW 30013 yang dihubungkan dengan elektrometer PTW Webline. Detektor ionisasi lainnya yang digunakan adalah detektor ionisasi volume $0,13 \mathrm{~cm}^{3}$ tipe IBA CC13 yang dihubungkan dengan elektrometer IBA Dose 1. Sedangkan alat ukur radiasi untuk lapangan kecil yang digunakan adalah detektor ionisasi volume $0,016 \mathrm{~cm}^{3}$ PTW Pinpoint 3D yang dihubungkan dengan elektrometer PTW Unidos Webline. Detektor ini direkomendasikan untuk pengukuran lapangan sampai dengan $2 \mathrm{~cm}$ x $2 \mathrm{~cm}$ (Hill, dkk. 2009; PTW, 2014). Spesifikasi teknis dari ketiga detektor tersebut dilihat pada Tabel 1.

Tabel 1. Karakteristik detektor ionisasi (IBA, 2011; PTW, 2015)

\begin{tabular}{lcccc}
\hline Detektor & $\begin{array}{c}\text { Volume Rongga } \\
\left(\mathbf{c m}^{\mathbf{3}}\right)\end{array}$ & $\begin{array}{c}\text { Panjang Rongga } \\
(\mathbf{m m})\end{array}$ & $\begin{array}{c}\text { Diameter Rongga } \\
(\mathbf{m m})\end{array}$ & Respon (nC/Gy) \\
\hline PTW TW 30013 & 0,6 & 23,0 & 6,1 & 20 \\
IBA CC13 & 0,13 & 5,8 & 6,0 & 3,6 \\
PTW $^{\mathrm{a}}$ 31016 & 0,016 & 2,9 & 1,45 & 0,4 \\
\hline
\end{tabular}

${ }^{a}$ ketebalan dinding PMMA $0,085 \mathrm{gr} / \mathrm{cm}^{2}$ 
Pengambilan data dilakukan di dalam fantom air 1D Scanner dengan dimensi $600 \mathrm{~mm}$ x 500 $\mathrm{mm} \times$ 407,5 mm. Untuk memantau kondisi ruang digunakan barometer Oakton dan termometer Digi Sense. Fantom 1D scanner dapat dilihat pada Gambar 2.

\subsection{Tata Kerja Eksperimen}

\subsubsection{Pengukuran Profil Berkas Radiasi}

Pengukuran profil berkas radiasi foton $6 \mathrm{MV}$ FFF dilakukan pada lapangan radiasi $2 \mathrm{~cm}$ x 2 $\mathrm{cm}$. pengukuran dilakukan pada kedalaman $10 \mathrm{~cm}$. Pengukuran ini dilakukan untuk mendapatkan nilai full width at half maximum (FWHM). Alat ukur yang digunakan untuk pengukuran relatif ini adalah perangkat pemindai IBA Blue Phantom2 yang dihubungkan dengan elektrometer CCU beserta perangkat lunak Omnipro-Accept versi 7.3. Detektor volume kecil yang digunakan adalah detektor PTW PinPoint 3D volume $0,016 \mathrm{~cm}^{3}$.

\subsubsection{Kalibrasi Monitor Unit Pesawat Pemercepat Linier Medik}

Kalibrasi monitor unit (MU) dilakukan untuk memastikan nilai $1 \mathrm{MU}$ dari pesawat memenuhi kriteria, yaitu $1 \mathrm{MU}=1 \mathrm{cGy}$. Pengukuran dilakukan menggunakan detektor ionisasi volume $0,6 \mathrm{~cm}^{3}$ tipe PTW TW 30013 no. seri 6367 yang dirangkaikan dengan elektrometer PTW Webline tipe T 10022. Detektor diletakkan pada kondisi acuan dengan kedalaman $10 \mathrm{~cm}$, jarak sumber radiasi ke permukaan fantom (source to surface distance/SSD) $100 \mathrm{~cm}$ dan lapangan radiasi (field size) pada permukaan fantom $10 \mathrm{~cm} \times 10 \mathrm{~cm}$.

Faktor koreksi polaritas, ion rekombinasi serta koreksi temperatur dan tekanan juga diukur. Hal ini diperlukan untuk melakukan perhitungan laju dosis serap air berkas foton 6 MV FFF sesuai dengan referensi (Pedro, dkk, 2006; IAEA, 2017).

\subsubsection{Kalibrasi Detektor dengan Metode Pengukuran Daisy Chaining}

Pengukuran dosis absolut pada lapangan radiasi kecil dapat dilakukan dengan syarat detektor lapangan radiasi kecil yang digunakan harus dikalibrasi silang terhadap detektor ukuran medium (PTW, 2014). Kemudian hasil kalibrasi silang tersebut digunakan untuk mengalibrasi silang detektor ionisasi ukuran kecil. Setelah kalibrasi silang dilakukan, detektor ukuran kecil dapat digunakan untuk mengukur dosis pada lapangan yang lebih kecil dari pada kondisi lapangan radiasi pada saat kalibrasi silang. Ilustrasi pengukuran daisy chaining dapat dilihat pada Gambar 1.

Kalibrasi silang dilakukan terhadap detektor ukuran medium terhadap detektor ukuran standar. Pada makalah ini detektor ionisasi ukuran medium IBA CC13 volume $0,13 \mathrm{~cm}^{3}$ dikalibrasi silang terhadap detektor ionisasi ukuran standar PTW TW 30013 tipe farmer volume $0,6 \mathrm{~cm}^{3}$. Kalibrasi silang dilakukan dengan metode substitusi pada SSD $100 \mathrm{~cm}$, lapangan radiasi $10 \mathrm{~cm}$ x $10 \mathrm{~cm}$ dengan kedalaman detektor $10 \mathrm{~cm}$. Berkas radiasi yang digunakan adalah berkas foton 6 MV FFF dengan 200 MU untuk penyinaran. Dari kalibrasi silang antara detektor IBA CC13 dengan detektor PTW TW 30013 didapatkan faktor kalibrasi dosis serap air $\left(\mathrm{N}_{\mathrm{D}, \mathrm{W}}\right)$ untuk detektor IBA CC13.

Faktor kalibrasi dosis serap air $\left(\mathrm{N}_{\mathrm{D}, \mathrm{w}}\right)$ dari detektor detektor IBA CC13 dengan detektor PTW TW 30013 digunakan untuk kalibrasi silang antara detektor ionisasi ukuran medium dengan detektor ionisasi ukuran kecil. Detektor ionisasi ukuran kecil yang digunakan adalah detektor PTW PinPoint 3D volume $0,016 \mathrm{~cm}^{3}$. Detektor PTW PinPoint 3D dikalibrasi silang terhadap detektor IBA CC13. Kondisi penyinaran dilakukan pada SSD $100 \mathrm{~cm}$, lapangan radiasi (field size) $5 \mathrm{~cm} \times 5 \mathrm{~cm}$ dengan kedalaman detektor $10 \mathrm{~cm}$. Dari kalibrasi silang antara detektor PTW PinPoint 3D dengan detektor IBA CC13 didapatkan faktor kalibrasi dosis serap air $\left(\mathrm{N}_{\mathrm{DW}}\right)$ untuk detektor PTW PinPoint 3D.

Hasil dari kalibrasi silang detektor ionisasi dengan menggunakan metode pengukuran daisy chaining adalah faktor kalibrasi serap air $\left(\mathrm{N}_{\mathrm{D}, \mathrm{W}}\right)$ untuk detektor PTW PinPoint 3D. Dengan menggunakan faktor kalibrasi serap air $\left(\mathrm{N}_{\mathrm{D}, \mathrm{W}}\right)$ tersebut, detektor PTW PinPoint 3D dapat digunakan untuk menentukan dosis serap air lapangan kecil (PTW, 2014).

Penentuan laju dosis serap lapangan kecil berkas foton 6 MV FFF pada lapangan kecil $2 \mathrm{~cm} \times$ $2 \mathrm{~cm}$ dan $3 \mathrm{~cm} \times 3 \mathrm{~cm} 1$ dengan SSD $100 \mathrm{~cm}$ dan kedalaman $10 \mathrm{~cm}$ dilakukan dengan detektor PTW PinPoint 3D. 


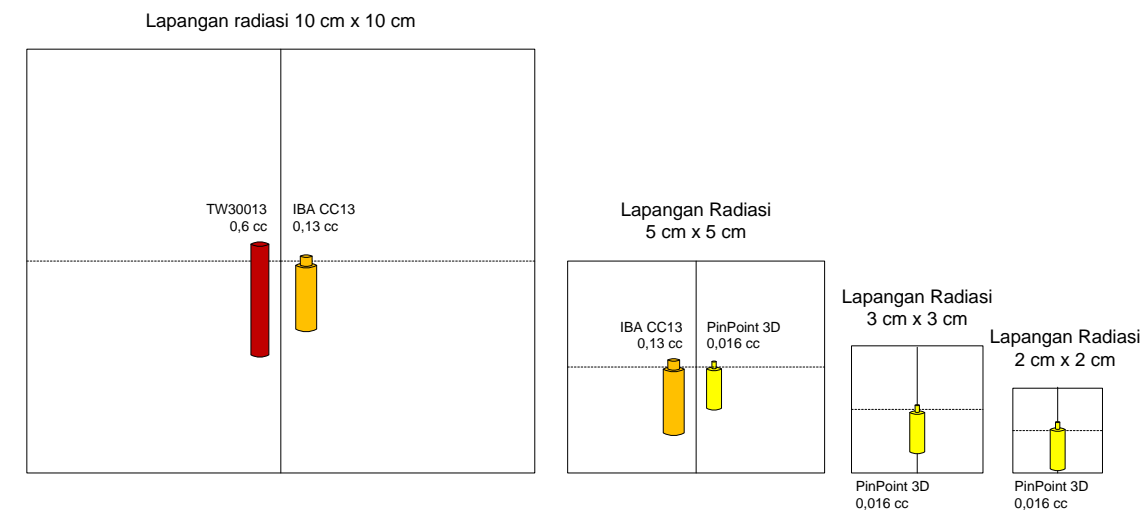

Gambar 1. Ilustrasi pengukuran dengan metode daisy chaining
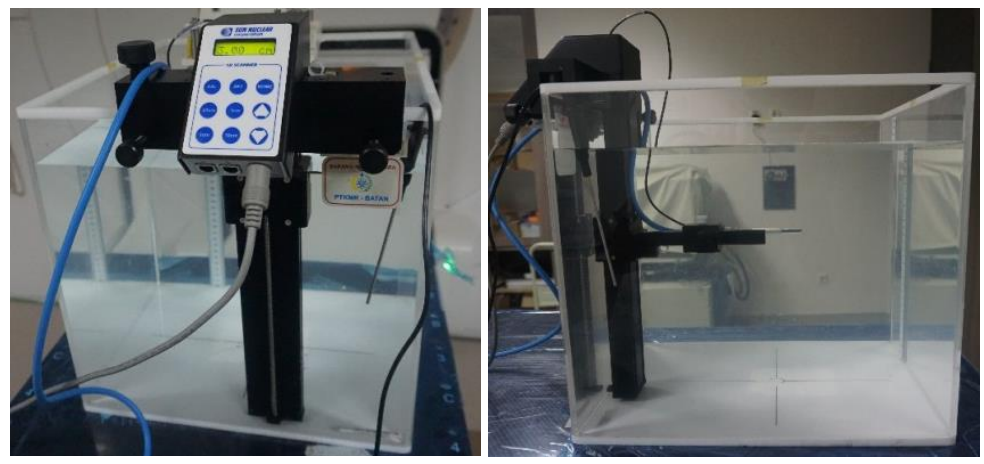

Gambar 2. Fantom air 1D Scanner

Penempatan masing-masing detektor pada saat kalibrasi ditempatkan pada titik pusat (iso center) lapangan radiasi. Selain itu, masing-masing detektor juga diatur sesuai denga titik referensi (reference point) pengukuran. Hal tersebut dimaksudkan untuk mereduksi adanya kesalahan terhadap penerimaan intensitas yang berbeda oleh masing-masing detektor pada saat kalibrasi. Metode ini juga dikenal dengan metode subtitusi (IAEA, 2000, 2009).

\section{HASIL DAN DISKUSI}

Hasil penentuan profil berkas radiasi foton 6 MV FFF pada kedalaman $10 \mathrm{~cm}$ mendapatkan nilai full width at half maximum (FWHM) sebesar $21,59 \mathrm{~mm}$. Sedangkan hasil pengukuran kualitas radiasi untuk $6 \mathrm{MV}$ FFF, didapatkan nilai $\mathrm{TPR}_{20 / 10}$ sebesar 0,632. Berdasarkan nilai tersebut, menggunakan Persamaan 2 didapatkan nilai $r_{L C P E}=0,907 \mathrm{~mm}$.

Sesuai dengan spesifikasi dari detektor PTW PinPoint 3D, hasil perhitungan untuk nilai $d$, didapatkan nilai 2,99 $\mathrm{mm}$ untuk geometri longitudinal $(d l)$, dan 3,08 $\mathrm{mm}$ untuk nilai geometri radial $(d r)$. Sesuai dengan referensi, nilai yang diambil untuk digunakan dalam persamaan 4 adalah nilai terbesar, berdasarkan hal tersebut maka $d r=d$ dengan nilai $3,08 \mathrm{~mm}$. Berdasarkan nilai tersebut, hasil dari persamaan 4 adalah nilai FWHM yaitu $21,59 \mathrm{~mm}$ lebih besar dari pada nilai $2 \mathrm{r}_{\mathrm{LCPE}}+d$ yaitu 4,894 $\mathrm{mm}$.

Hasil tersebut memberikan konklusi bahwa detektor PTW PinPoint 3D dapat digunakan untuk melakukan pengukuran di lapangan kecil $2 \mathrm{~cm} \times 2 \mathrm{~cm}$. Hal itu dapat terjadi karena pada kondisi tersebut kesetimbangan partikel bermuatan di lateral untuk detektor PTW PinPoint 3D masih dapat dicapai (IAEA, 2017). Kemampuan ini juga sama dengan rekomendasi pabrik yang menyatakan detektor PinPoint 3D dapat digunakan untuk melakukan pengukuran hingga lapangan radiasi $2 \mathrm{~cm} \times 2$ cm (PTW, 2014).

Hasil penentuan laju dosis serap air berkas foton 6 MV FFF pada kondisi acuan dengan jarak sumber radiasi ke permukaan $100 \mathrm{~cm}$ dan lapangan radiasi $10 \mathrm{~cm}$ x $10 \mathrm{~cm}$ dapat dilihat pada Tabel 2 di bawah ini. 
Tabel 2 Hasil penentuan laju dosis serap air berkas foton 6 MV FFF pada kondisi acuan dengan jarak sumber radiasi ke permukaan $100 \mathrm{~cm}$ dan lapangan radiasi $10 \mathrm{~cm} \times 10 \mathrm{~cm}$.

\begin{tabular}{ll}
\hline Parameter & Nilai \\
\hline $\mathrm{M}_{\mathrm{Q}}(\mathrm{nC})$ & 23,525 \\
\hline $\mathrm{N}_{\mathrm{D}, \mathrm{W}}(\mathrm{mGy} / \mathrm{nC})$ & 53,92 \\
\hline $\mathrm{TPR}_{20 / 10}$ & 0,632 \\
\hline $\mathrm{K}_{\mathrm{pol}}$ & 1,0007 \\
\hline $\mathrm{K}_{\mathrm{S}}$ & 1,0045 \\
\hline $\mathrm{K}_{\mathrm{Q}}$ & 0,9949 \\
\hline $\mathrm{D}_{10}(\mathrm{mGy} / 200 \mathrm{MU})$ & 1268,6 \\
\hline $\mathrm{PDD}_{10}(\%)$ & 63,39 \\
\hline $\mathrm{D}_{\max }(\mathrm{mGy} / 200 \mathrm{MU})$ & $2001,3 \pm 2,4 \%$ \\
\hline
\end{tabular}

Pada penentuan laju dosis serap air, faktor koresi polaritas (Kpol), faktor koreksi ion rekombinasi (KS) dan faktor koreksi kualtias radiasi (KQ) sangatlah penting. Dari hasil pengukuran, didapatkan nilai Kpol sebesar 1,0008, nilai KS sebesar 1,002 dan nilai KQ sebesar 0,9918. Nilai KQ didapatkan dari tabel yang disediakan di IAEA TRS-483 sesuai dengan jenis detektor dan kualitas radiasi yang didapatkan $\left(\mathrm{TPR}_{20 / 10}\right)$. Nilai $\mathrm{TPR}_{20 / 10}$ yang didapatkan adalah 0,632 .

Dari Tabel 2 dapat dilihat bahwa laju dosis serap air maksimum mendapatkan nilai 2001,9 mGy/200 MU. Dengan hasil tersebut, hasil kalibrasi monitor unit (MU) sudah sesuai karena mendapatkan deviasi sebesar $0,06 \%$ terhadap $1 \mathrm{MU}=1 \mathrm{cGy}$.

Hasil kalibrasi silang detektor volume medium IBA CC13 terhadap detektor standar volume $0,6 \mathrm{cc}$ untuk berkas foton $6 \mathrm{MV}$ FFF pada lapangan radiasi $10 \mathrm{~cm} \times 10 \mathrm{~cm}$ dengan jarak sumber radiasi ke permukaan $100 \mathrm{~cm}$ dapat dilihat pada Tabel 3 di bawah ini, sedangkan hasil kalibrasi detektor volume kecil PTW PinPoint 3D terhadap detektor volume medium IBA CC13 pada lapangan radiasi $5 \mathrm{~cm} \times 5 \mathrm{~cm}$ dapat dilihat pada Tabel 4 .

Tabel 3 Hasil kalibrasi silang detektor volume medium IBA CC13 terhadap detektor standar volume $0,6 \mathrm{~cm}^{3}$ TW30013 untuk berkas foton 6 MV FFF pada lapangan radiasi $10 \mathrm{~cm}$ x $10 \mathrm{~cm}$.

\begin{tabular}{lllcc}
\hline Detektor & Bacaan $(\mathbf{n C})$ & $\begin{array}{l}\text { Faktor Kalibrasi } \\
(\mathbf{m G y} / \mathbf{n C})\end{array}$ & $\mathbf{K}_{\mathbf{Q}, \mathbf{Q}}$ & $\begin{array}{l}\text { Faktor Kalibrasi } \\
(\mathbf{m G y} / \mathbf{n C})\end{array}$ \\
\hline TW 30013 $\left(0,6 \mathrm{~cm}^{3}\right.$ & 23,52 & 53,92 & 0,994895 & 269,2 \\
IBA CC13 $\left(0,13 \mathrm{~cm}^{3}\right)$ & 4,687 & - & - & \\
\hline
\end{tabular}

Tabel 4 Hasil kalibrasi silang detektor volume kecil PTW Pinpoint 3D terhadap detektor volume medium IBA CC13 untuk berkas foton 6 MV FFF pada lapangan radiasi $5 \mathrm{~cm} \times 5 \mathrm{~cm}$.

\begin{tabular}{llll}
\hline Detektor & Bacaan $(\mathbf{n C})$ & $\begin{array}{l}\text { Faktor Kalibrasi } \\
(\mathbf{m G y} / \mathbf{n C})\end{array}$ & $\begin{array}{l}\text { Faktor Kalibrasi } \\
(\mathbf{m G y} / \mathbf{n C})\end{array}$ \\
\hline IBA CC13 $\left(0,13 \mathrm{~cm}^{3}\right)$ & 23,52 & 269,2 & 2502,7 \\
PTW Pinpoint 3D $\left(0,016 \mathrm{~cm}^{3}\right)$ & 0,4554 & - & \\
\hline
\end{tabular}

Hasil kalibrasi silang antara detektor standar TW 30013 volume $0,6 \mathrm{~cm}^{3}$ dengan detektor medium IBA CC13 volume $0,13 \mathrm{~cm}^{3}$ didapatkan nilai faktor kalibrasi dosis serap air $\left(\mathrm{N}_{\mathrm{D}, \mathrm{w}}\right) 269,2$ $\mathrm{mGy} / \mathrm{nC}$. Faktor kalibrasi dosis serap air (ND,W) IBA CC13 pada lapangan standar $10 \mathrm{~cm} \times 10 \mathrm{~cm}$ tersebut digunakan untuk kalibrasi silang dengan detektor ionisasi ukuran kecil yaitu PTW Pinpoint 3D. Kalibrasi silang berikutnya antara detektor IBA CC13 dan PTW PinPoint 3D dilakukan di lapangan radiasi $5 \mathrm{~cm} \times 5 \mathrm{~cm}$. Sesuai dengan tabel 4 didapatkan faktor kalibrasi dosis serap air (ND,W) untuk detektor PTW PinPoint 3D sebesar 2502,7 mGy/nC. Nilai ini dapat digunakan untuk melakukan pengukuran dosis pada kondisi lapangan dibawah $5 \mathrm{~cm}$ x $5 \mathrm{~cm}$ (kondisi lapangan radiasi pada kalibrasi silang) dengan variasi kedalaman pengukuran tetapi pada kualitas radiasi dan arah orientasi pemasangan detektor yang sama (PTW, 2014). 
Dengan menggunakan faktor kalibrasi dosis serap air $\left(\mathrm{N}_{\mathrm{D}, \mathrm{W}}\right)$ PTW PinPoint 3D sebesar 2502,7 $\mathrm{mGy} / \mathrm{nC}$, penentuan laju dosis serap air berkas foton $6 \mathrm{MV}$ FFF dilakukan. Pengukuran dilakukan pada jarak sumber radiasi ke permukaan fantom $100 \mathrm{~cm}$ dengan lapangan radiasi $2 \mathrm{~cm} \times 2 \mathrm{~cm}$ dan 3 $\mathrm{cm}$ x $3 \mathrm{~cm}$. Hasil pengukuran dapat dilihat pada Tabel 5 .

Tabel 5 Hasil penentuan laju dosis serap air berkas foton 6 MV FFF, SSD $100 \mathrm{~cm}$ dengan lapangan radiasi $3 \mathrm{~cm} \times 3 \mathrm{~cm}$ dan $2 \mathrm{~cm} \times 2 \mathrm{~cm}$.

\begin{tabular}{lll}
\hline Parameter & & Nilai \\
\hline Field Size $\left(\mathrm{cm}^{2}\right)$ & $2 \times 2$ & $3 \times 3$ \\
\hline $\mathrm{M}_{\mathrm{Q}}(\mathrm{nC})$ & 0,4089 & 0,4296 \\
\hline $\mathrm{N}_{\mathrm{D}, \mathrm{w}}(\mathrm{mGy} / \mathrm{nC})$ & 2502,7 & 2502,7 \\
\hline $\mathrm{K}_{\mathrm{pol}}$ & 1,0096 & 1,009 \\
\hline $\mathrm{K}_{\mathrm{S}}$ & 1,0051 & 1,0048 \\
\hline $\mathrm{D}_{10}(\mathrm{mGy} / 200 \mathrm{MU})$ & 1023,54 & 1075,17 \\
\hline $\mathrm{PDD}_{10}(\%)$ & 63,39 & 63,39 \\
\hline $\mathrm{D}_{\max }(\mathrm{mGy} / 200 \mathrm{MU})$ & 1615 & 1696 \\
\hline $\mathrm{MU}(\mathrm{cGy} / \mathrm{MU})$ & 0,8073 & 0,8481 \\
\hline $\mathrm{TPS}(\mathrm{cGy} / \mathrm{MU})$ & 0,830 & 0.868 \\
\hline
\end{tabular}

Pada lapangan radiasi $3 \mathrm{~cm}$ x $3 \mathrm{~cm}$ didapatkan laju dosis serap air maksimum sebesar 1696 mGy/200 MU yang berarti mendapatkan nilai 0,8481 cGy/MU. Sedangkan untuk lapangan radiasi 2 $\mathrm{cm}$ x $2 \mathrm{~cm}$ didapatkan laju dosis serap air maksimum sebesar 1615 mGy/200 MU yang berarti mendapatkan nilai $0,8073 \mathrm{cGy} / \mathrm{MU}$.

Hasil dari pengukuran dengan menggunakan detektor ionisasi juga dibandingkan dengan hasil komputasi dosis yang dilakukan oleh treatment planning system (TPS). TPS yang digunakan adalah TPS Eclipse 13.6. Pada penelitian ini penulis belum melakukan verifikasi terhadap perhitungan dosis yang dilakukan oleh TPS, sehingga nilai TPS belum dapat dijadikan sebagai acuan nilai benar.

Dari Tabel 4 di atas dapat dilihat bahwa untuk lapangan radiasi $3 \mathrm{~cm} \mathrm{x} 3 \mathrm{~cm}$, hasil perhitungan TPS mendapatkan nilai 0,868 cGy/MU, sedangkan hasil pengukuran dengan detektor ionisasi PTW Pinpoint 3D mendapatkan nilai 0,8481 cGy/MU. Dari data tersebut didapatkan deviasi sebesar 2,29\% antara nilai dari TPS dan pengukuran dengan detektor PTW Pinpoint 3D pada lapangan $3 \mathrm{~cm} \times 3 \mathrm{~cm}$.

Untuk lapangan radiasi $2 \mathrm{~cm} \times 2 \mathrm{~cm}$, hasil perhitungan TPS mendapatkan nilai 0,830 , sedangkan hasil pengukuran dengan detektor ionisasi PTW Pinpoint 3D mendapatkan nilai 0,8073. Dengan demikian terdapat deviasi sebesar $2,73 \%$ antara nilai dari TPS dan pengukuran dengan detektor PTW Pinpoint 3D pada lapangan $2 \mathrm{~cm} \times 2 \mathrm{~cm}$.

Tabel 6 Hasil penentuan laju dosis serap air berkas foton 6 MV FFF secara langsung, SSD $100 \mathrm{~cm}$ dengan lapangan radiasi $3 \mathrm{~cm} \times 3 \mathrm{~cm}$ dan $2 \mathrm{~cm} \times 2 \mathrm{~cm}$.

\begin{tabular}{lll}
\hline Parameter & \multicolumn{2}{c}{ Nilai } \\
\hline Field Size $\left(\mathrm{cm}^{2}\right)$ & $2 \times 2$ & $3 \times 3$ \\
\hline $\mathrm{M}_{\mathrm{Q}}(\mathrm{nC})$ & 0,4089 & 0,4296 \\
\hline $\mathrm{N}_{\mathrm{D}, \mathrm{W}}(\mathrm{mGy} / \mathrm{nC})$ & 2520 & 2520 \\
\hline $\mathrm{K}_{\mathrm{pol}}$ & 1,0096 & 1,009 \\
\hline $\mathrm{K}_{\mathrm{S}}$ & 1,0051 & 1,0048 \\
\hline $\mathrm{D}_{10}(\mathrm{mGy} / 200 \mathrm{MU})$ & 1030 & 1082 \\
\hline $\mathrm{PDD}_{10}(\%)$ & 63,39 & 63,39 \\
\hline $\mathrm{D}_{\max }(\mathrm{mGy} / 200 \mathrm{MU})$ & 1626 & 1708 \\
\hline $\mathrm{MU}(\mathrm{cGy} / \mathrm{MU})$ & 0,808 & 0,849 \\
\hline $\mathrm{TPS}(\mathrm{cGy} / \mathrm{MU})$ & 0,830 & 0.866 \\
\hline
\end{tabular}


Sesuai dengan referensi (PTW, 2014), detektor ionisasi juga dapat digunakan secara langsung untuk melakukan pengukuran dosis pada lapangan kecil. Verifikasi pengukuran secara langsung juga dilakukan dan dibandingkan dengan perhitungan yang dilakukan oleh TPS seperti sebelumnya.

Hasil pengukuran secara langsung dengan menggunakan detektor PTW Pinpoint 3D pada berkas foton $6 \mathrm{MV}$ FFF di lapangan $2 \mathrm{~cm} \times 2 \mathrm{~cm}$ dan $3 \mathrm{~cm} \times 3 \mathrm{~cm}$ dapat dilihat pada Tabel 6 . Detektor PTW Pinpoint 3D yang digunakan telah dikalibrasi langsung pada lapangan $10 \mathrm{~cm} \times 10 \mathrm{~cm}$ pada berkas foton $6 \mathrm{MV}$ FF dengan $\mathrm{TPR}_{20 / 10} 0,667$.

Pada lapangan radiasi $3 \mathrm{~cm} \times 3 \mathrm{~cm}$ didapatkan laju dosis serap air maksimum sebesar 1626 $\mathrm{mGy} / 200 \mathrm{MU}$ yang berarti mendapatkan nilai 0,808 cGy/MU. Sedangkan untuk lapangan radiasi $2 \mathrm{~cm}$ $\times 2 \mathrm{~cm}$ didapatkan laju dosis serap air maksimum sebesar $1708 \mathrm{mGy} / 200 \mathrm{MU}$ yang berarti mendapatkan nilai $0,849 \mathrm{cGy} / \mathrm{MU}$.

Dari Tabel 7 dapat dilihat bahwa untuk lapangan radiasi $3 \mathrm{~cm} \times 3 \mathrm{~cm}$, hasil perhitungan TPS Eclipse 13.6 mendapatkan nilai 0,868 cGy/MU, sedangkan hasil pengukuran dengan detektor ionisasi PTW Pinpoint 3D mendapatkan nilai 0,849 cGy/MU. Dari data tersebut didapatkan deviasi sebesar 1,96\% antara nilai dari TPS Eclipse 13.6 dan pengukuran dengan detektor PTW Pinpoint 3D pada lapangan $3 \mathrm{~cm} \times 3 \mathrm{~cm}$.

Untuk lapangan radiasi $2 \mathrm{~cm} \times 2 \mathrm{~cm}$, hasil perhitungan TPS mendapatkan nilai 0,830 , sedangkan hasil pengukuran dengan detektor ionisasi PTW Pinpoint mendapatkan nilai 0,808. Dengan demikian terdapat deviasi sebesar 2,65\% antara nilai dari TPS Eclipse 13.6 dan pengukuran dengan detektor PTW Pinpoint 3D pada lapangan $2 \mathrm{~cm} \times 2 \mathrm{~cm}$.

Tabel 7 Hasil penentuan dosis per monitor unit (cGy/MU) dengan perbandingan metode pengukuran langsung, tidak langsung (daisy chaining) dan verifikasi terhadap TPS

\begin{tabular}{lcc}
\hline \multirow{2}{*}{ Parameter } & \multicolumn{2}{c}{ Nilai Dosis per Monitor Unit (cGy/MU) } \\
\cline { 2 - 3 } & $\begin{array}{c}\text { Lapangan Radiasi } \\
\mathbf{2} \mathbf{~ c m ~} \times \mathbf{2} \mathbf{~ c m}\end{array}$ & $\begin{array}{c}\text { Lapangan Radiasi } \\
\mathbf{3} \mathbf{~ c m} \times \mathbf{3} \mathbf{~ c m}\end{array}$ \\
\hline Pengukuran langsung dengan detektor PTW PinPoint 3D & 0.808 & 0.849 \\
\hline $\begin{array}{l}\text { Pengukuran dengan detektor PTW PinPoint 3D hasil dari } \\
\text { metode Daisy Chaining }\end{array}$ & 0.807 & 0.848 \\
\hline Perhitungan TPS Eclipse 13.6 & 0.83 & 0.868 \\
\hline
\end{tabular}

Dapat dilihat bahwa deviasi yang diperoleh padd lapangan kecil $2 \mathrm{~cm} \times 2 \mathrm{~cm}$ lebih besar dari pada lapangan $3 \mathrm{~cm} \times 3 \mathrm{~cm}$. Hal tersebut terjadi baik pada pengukuran langsung menggunakan detektor PTW PinPoint 3D maupun pengukuran tidak langsung dengan menggunakan faktor kalibrasi dosis serap air $\left(\mathrm{N}_{\mathrm{D}, \mathrm{W}}\right)$ detektor PTW PinPoint 3D hasil dari pengukuran daisy chaining. Semakin kecil lapangan radiasi, semakin besar pula potensi tidak tercapainya kesetimbangan partikel bermuatan. Terjadinya efek volume juga merupakan salah satu tantangan pengkuran dosis pada lapangan kecil (Wuerfel, 2013)(Sharma, 2014).

\section{KESIMPULAN}

Berdasarkan penelitian mengenai pengukuran daisy chaining untuk mendapatkan faktor kalibrasi detektor ionisasi volume kecil pada berkas foton 6 MV FFF dapat disimpulkan bahwa terdapat kesesuaian yang cukup baik laju dosis serap air yang ditentukan berdasarkan pengukuran daisy chaining maupun pengukuran langsung dengan menggunakan detektor ionisasi PTW PinPoint 3D terhadap perhitungan TPS Eclipse 13.6 dengan kecenderungan hasil pengukuran mendapatkan nilai yang lebih rendah.

\section{UCAPAN TERIMA KASIH}

Penulis mengucapkan terima kasih kepada Unit Radioterapi Rumah Sakit Umum Daerah Pasar Minggu atas kerjasamanya sehingga penulisan ini dapat terlaksana. 


\section{DAFTAR PUSTAKA}

Andreo, P. (2017). The physics of small megavoltage photon beam dosimetry. Radiotherapy and Oncology, 126(2), 205-2013.

Assef F F; Gatot W; Nurman R; Sri I S. (2017). Perkembangan Teknologi Pada Pesawat Teleterapi di Indonesia dan Aspek Keselamatannya. In Seminar Keselamatan Nuklir (pp. 257-262). Yogyakarta.

Borzov, E., Nevelsky, A., Bar-Deroma, R., \& Orion, I. (2018). Dosimetric characterization of Elekta stereotactic cones. Journal of Applied Clinical Medical Physics, 19(1), 194-203.

Das, I. J. (2014). Small Field Dosimetry: An Overview of Reference and Relative Dosimetry in Non-Equilibrium Condition. AAPM Summer School.

Das, I. J., \& Francescon, P. (2018). Comments on the TRS 483 protocol on small field dosimetry. In Medical Physics (Vol. 45, pp. 5666-5668).

Dieterich, S., \& Sherouse, G. W. (2011). Experimental comparison of seven commercial dosimetry diodes for measurement of stereotactic radiosurgery cone factors. Medical Physics, 38(7), 4166-4173.

Firmansyah, A. F., Nasution, I., Sri, D., \& Sunaryati, I. (2017). Karakteristik Berkas Radiasi Foton 6 MV dan 10 MV Tanpa Flattening Filter dari Pesawat Pemercepat Linier Medik Versa HD. In Prosiding Pertemuan dan Presentasi Ilmiah Penelitian Dasar Ilmu Pengetahuan dan Teknologi Nuklir (PSTA BATAN) (pp. 245-250).

Firmansyah, A. F., Sunaryati, I., Rajagukuguk, N., \& Ryangga, D. (2018). Karakteristik Berkas Foton 6 MV Tanpa Flattening Filter Pesawat Pemercepat Linier Medik Varian Trilogy. In Pertemuan Ilmiah Tahunan Fisika Medis dan Biofisika (pp. 222-226).

Firmansyah, A. F., Sunaryati, S. I., Rajagukuguk, N., Firmansyah, O. A., \& Asril, yosi sudarsi. (2019). Kalibrasi Luaran Berkas Foton 6 dan 10 MV tanpa Flattening Filter Pesawat Pemercepat Linier Medik Elekta Versa HD dengan menggunakan TRS No, 483. In Prosiding Seminar Keselamatan Nuklir 2019 (p. 395).

Hill, R., Mo, Z., Haque, M., \& Baldock, C. (2009). An evaluation of ionization chambers for the relative dosimetry of kilovoltage x-ray beams. Medical Physics, 36(9), 3971-3981.

IAEA. (2000). IAEA SRS-16: Safety Report Series Calibration of Radiation Protection Monitoring Instrument.

IAEA. (2009). IAEA TRS 469: Calibration of Reference Dosimeters for External Beam Radiotherapy.

IAEA. (2017). IAEA TRS-483: Dosimetry of Small Static Fields Used in External Beam Radiotherapy: An Code of Practice for reference and Relative Dose Determination.

IBA Dosimetry. (2011). Detectors for Relative and Absolute Dosimetry - Ionization Chambers and Diode Detectors.

Kajaria, A., Sharma, N., \& Sharma, S. (2016). Study of the Dosimetric Properties of an Unflattened 6-MV Photon Beam By Using the BEAMnrc Code. Journal of the Korean Physical Society, 69(4), 657-665.

Lárraga-Gutiérrez, J. M. (2015). Experimental determination of field factors for small radiotherapy beams using the daisy chain correction method. Physics in Medicine and Biology, 60(15), 5813-5831.

Lauba, W. U., \& Wong, T. (2003). The volume effect of detectors in the dosimetry of small fields used in IMRT. Medical Physics, 30(3), 341-347.

Liu, P. Z. Y., Reggiori, G., Lobefalo, F., Mancosu, P., Tomatis, S., Mckenzie, D. R., \& Suchowerska, N. (2016). Small field correction factors for the IBA Razor. Physica Medica, 32(8), 1025-1029.

Looe, H. K., Harder, D., Rühmann, A., Willborn, K. C., \& Poppe, B. (2010). Enhanced accuracy of the permanent surveillance of IMRT deliveries by iterative deconvolution of DAVID chamber signal profiles. Physics in Medicine and Biology, 55(14), 3981-3992.

Papanikolaou, N., \& Stathakis, S. (2016). Commissioning an Elekta Versa HD linear accelerator. Journal of Appied Clinical Medical Physics, 17(1), 179-191.

Pedro Andreo, David T Burns, Klaus Hohlfeld, M Saiful Huq, Tatsuaki Kanai, Fedele Laitano, Vere Smyth, S. V. (2006). IAEA TRS-398: Absorbed Dose Determination in External Beam Radiotherapy: An International Code of Practice for Dosimetry based on Standards of Absorbed Dose to Water (Vol. 2006).

Poppinga, D., Delfs, B., Meyners, J., Harder, D., Poppe, B., \& Looe, H. K. (2018). The output factor correction as function of the photon beam field size - direct measurement and calculation from the lateral dose response functions of gas-filled and solid detectors. Zeitschrift Für Medizinische Physik, 28(Agustus), 224-235.

PTW. (2014). Small Field Dosimetry: Application Guide.

PTW. (2015). Manual Book: PTW Detectors.

Purohit, S., Kabir, S. M. E., Rahman, M. S., Patwary, M. K. A., Meaze, A. K. M. M. H., Jahan, I., Paul, D. (2018). A Study of Measurement of Relative Dose With Various Chamber for Small Field Dosimetry of 6 MV Photon Beam A Study of Measurement of Relative Dose With Various Chamber for Small Field Dosimetry of $6 \mathrm{MV}$ Photon Beam. Nuclear Science and Applications, 26(March), 23-27.

Sharma, S. D. (2014). Challenges of small photon field dosimetry are still challenging. Journal of Medical Physics, $39(3), 131-132$.

Wuerfel, J. U. (2013). Dose Measurements In Small Fields. Medical Physics International Journal, 1(1), 81-90. 